\title{
Manajemen Risiko: Insiden Kritis Akibat COVID-19 pada Kedai Makanan di Sekitar Kampus Universitas Kristen Petra Surabaya
}

\author{
Graciella Valentina ${ }^{1}$, Pwee Leng ${ }^{2}$ \\ ${ }^{12}$ Program Finance and Investment, Universitas Kristen Petra Surabaya \\ E-mail: d11170440@john.petra.ac.id
}

\begin{abstract}
This study aims to determine risk management in the food and beverage business around Petra Christian University (PCU) Surabaya. There was a critical incident of COVID-19 so this research was conducted with the aim of producing reports for business owners related to risk management in business operations. The risk management process consists of stages of risk identification, risk analysis, risk evaluation, and risk management. The population used in this study is food and beverage shop that are easily accessible around PCU with the main target of consumers are students, and PCU employees that is still open the business in the midst of the COVID-19 pandemic. There are only 3 shops out of dozens of food and beverage shops that experienced critical incidents due to PCU implementing online learning which still lasted until this research was conducted. Those risks are spread across 3 different business categories, namely main business process, essential business process, and supporting business process. The majority of risks are in the category of supporting business processes. The same risk can be spread across different risk categories in each foods and beverage shop, this is due to the different risk appetite of each shop.
\end{abstract}

Keywords: Food and Beverage Shop, Operational Risk, Risk Management

Abstrak

Penelitian ini bertujuan untuk mengetahui manajemen risiko pada bisnis makanan dan minuman di sekitar Universitas Kristen Petra (UKP) Surabaya. Adanya kejadian kritis COVID-19 sehingga penelitian ini dilakukan dengan tujuan untuk menghasilkan laporan bagi pemilik usaha terkait dengan manajemen risiko pada operasional bisnis. Proses manajemen risiko terdiri dari tahapan identifikasi risiko, analisis risiko, evaluasi risiko, dan penanganan risiko. Populasi yang digunakan dalam penelitian ini adalah kedai makanan yang mudah dijangkau di sekitar UKP dengan mayoritas konsumennya mahasiswa, dan karyawan UKP yang masih membuka usaha di tengah pandemi COVID-19. Hanya terdapat 3 kedai makanan dari beberapa kedai makanan yang mengalami kejadian kritis akibat UKP menerapkan kuliah secara online yang masih bertahan hingga penelitian ini dilakukan. Risiko-risiko tersebut tersebar di 3 kategori bisnis yang berbeda yaitu proses bisnis utama, proses bisnis penunjang, dan proses bisnis pendukung. Mayoritas risiko berada pada kategori proses bisnis pendukung. Risiko yang sama dapat tersebar pada kategori risiko yang berbeda di setiap kedai makanan, hal ini disebabkan oleh selera risiko yang berbeda dari setiap kedai makanan.

\section{Kata Kunci: Kedai Makanan, Manajemen Risiko, Risiko Operasional}

(C) 2021 Jurnal Riset Inspirasi Manajemen dan Kewirausahaan

\section{PENDAHULUAN}

Pandemi COVID-19 masuk pertama kali di Indonesia pada Bulan Maret 2020, sehingga Indonesia memberlakukan karantina mandiri, dan pembatasan interaksi langsung satu sama lain. Hal ini berdampak pada sektor perekonomian, seperti Badan Pusat Statistik (BPS) mencatat Produk Domestik Bruto (PDB) Indonesia tahun 2020 mencapai Rp 15.434,2 triliun, dan terjadi kontraksi sebesar $2,07 \%$ pada pertumbuhan di Indonesia tahun 2020. Badan Ekonomi Kreatif mencatat tahun 2018 usaha kuliner di Indonesia mencapai $67,66 \%$ dari total 8,20 juta ekonomi usaha kreatif, dan $60 \%$ dari usaha kuliner yang terdampak COVID-19 memutuskan untuk menutup usahanya.
BPS Provinsi Jawa Timur mencatat pertumbuhan ekonomitahun 2020 mengalami kontraksi 2,39\%, dan di Surabaya tercatat jumlah pengangguran meningkat sebanyak 466.000 pada tahun 2020. Inflasi di Surabaya sebesar $0,29 \%$, dimana inflasi ini merupakan inflasi tertinggi jika dibandingkan dengan kota lainnya di Jawa Timur. Selain berdampak pada perekonomian, COVID-19 juga mempengaruhi aktivitas belajar mengajar di lembaga pendidikan, salah satunya adalah Universitas Kristen Petra (UKP) Surabaya yang menerapkan kebijakan pembelajaran secara online. UKP berlokasi di Siwalankerto, dimana wilayah ini tergolong ramai dikarenakan berdekatan dengan pemukiman warga. Selain itu, di sekitar UKP banyak terdapat kos-kos mahasiswa sehingga banyak terdapat toko-toko yang menjual kebutuhan mahasiswa, seperti 
kedai makanan, tempat kopi, tempat fotocopy, dan tempat untuk cuci baju. Mayoritas target pasar dari usaha-usaha tersebut adalah mahasiswa, dan civitas akademika UKP dimana dengan penetapan kuliah online mengakibatkan banyaknya mahasiswa yang memutuskan untuk keluar dari kos, dan kembali ke kampung halamannya. Hal ini mengakibatkan kedai makanan yang memutuskan untuk menutup usahanya tercatat kurang lebih 90\%, dimana kedai makanan tersebut telah berhenti beroperasi sejak pertengahan tahun 2020. Saat ini, terdapat 3 kedai makanan yang memiliki target pasar utama mahasiswa dan civitas akademika UKP dan masih beroperasi, yaitu KFB, DG, dan SC.

COVID-19 merupakan insiden yang tidak biasa, belum pernah terjadi sebelumnya, tidak dapat diprediksi kapan berakhir, dan mempengaruhi operasional usaha kedai makanan. Dengan fakta tersebut, maka besar kemungkinan pemilik usaha tidak pernah memikirkan adanya risiko Covid-19 yang dapat mempengaruhi operasional usahanya. Oleh karena itu, keputusan kedai makanan untuk tetap membuka usahanya di tengah pandemi COVID-19 ini tentu perlu mempertimbangkan adanya kemungkinan risiko yang ada. Risiko merupakan sesuatu ketidakpastian, dan penyimpangan yang dapat mempengaruhi kinerja, modal, pendapatan, hingga memungkinkan terjadinya kebangkrutan. Hal ini menunjukkan penting adanya manajemen risiko yang dilakukan untuk mengetahui risiko operasional apa saja yang dihadapi oleh kedai makanan, dan bagaimana cara menghadapi risiko tersebut. Dengan manajemen risiko yang tepat, maka besar kemungkinan kedai makanan dapat mempertahankan operasional usahanya, dan dapat menjadi bentuk antisipasi apabila hal serupa yang tidak dapat diprediksi terjadi kembali di kemudian hari.

\section{KAJIAN LITERATUR}

\section{Manajemen Risiko}

Manajemen risiko merupakan suatu proses yang sistematis dan terstruktur yang dilakukan dengan mengidentifikasi, mengukur, memetakan, mengembangkan alternatif dalam mengidentifikasi, menangani, dan memonitor suatu risiko (Fatoki \& Olawale, 2014).

Duckert (2011) dalam metodenya memetakan risiko menjadi 3 kategori sebagai berikut :

1. Proses Bisnis Utama (Core)

Mencakup tanggung jawab untuk menghasilkan uang, dan mengelolanya dengan efisien untuk memenuhi kepentingan serta semua bagian dari operasional usaha.

2. Proses Bisnis Pendukung (CSU)

Mencakup fungsi yang mendukung efisiensi suatu perusahaan, seperti TI, penelitian, pengembangan, teknik, manajemen rantai pasokkan, penjaminan emisi, dan aktuaria,

3. Proses Bisnis Penunjang (Periphery)

Mencakup fungsi yang timbul karena proses bisnis utama, dan mendukung agar berjalan efektif, dan efisien seperti sumber daya manusia, keuangan, pajak, dan hukum.

Risiko operasional merupakan risiko yang timbul akibat adanya penyimpangan pada sistem, proses internal perusahaan, sumber daya manusia (SDM), pelanggaran hukum, dan faktor eksternal (Djohanputro, 2006).

Manajemen risiko penting untuk diterapkan untuk meningkatkan kemungkinan mencapai tujuan usaha, mendorong kinerja manajemen, efisiensi, dan efektivitas, serta mengurangi potensi kerugian dari risiko operasional maupun risiko terduga seperti COVID-19.

\section{Proses Manajemen Risiko}

Proses manajemen risiko terdiri dari tahap identifikasi risiko, analisa risiko, evaluasi risiko, dan penanganan risiko (ISO 31000, 2018). Proses manajemen risiko dapat dilihat pada gambar 1.

1. Identifikasi risiko dilakukan untuk mengetahui risiko yang dihadapi oleh pelaku bisnis yang berpotensi mempengaruhi kemajuan serta keberlangsungan usaha tersebut.

2. Analisa risiko untuk mengetahui tingkat kemungkinan risiko, dan dampak dari risiko, kemudian dapat dibentuk pemetaan / matriks risiko.

3. Evaluasi risiko dilakukan untuk menentukan risiko yang memerlukan penanganan lebih lanjut, dan risiko yang tidak memerlukan penanganan lebih lanjut. Keputusan ini diambil berdasarkan level risiko, yaitu dapat diterima, dipantau, pengendalian manajemen, menjadi perhatian manajemen, dan tidak dapat diterima (Moeller, 2009).

4. Penanganan risiko dilakukan untuk memilih, dan menerapkan opsi penanganan risiko, seperti menghindari risiko (risk avoidance), menerima risiko (accepting the risk), mengalihkan risiko (risk transfer), dan mengurangi risiko (risk reducing) terhadap risiko yang ada.

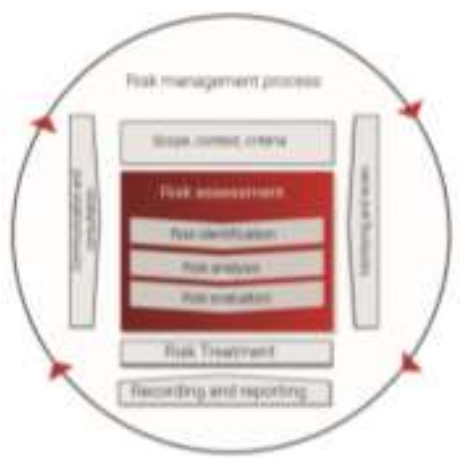




\section{Gambar 1. Proses Manajemen Risiko Sumber: ISO 31000:2018 METODE PENELITIAN}

Populasi yang digunakan dalam penelitian ini adalah kedai makanan di sekitar UKP yang masih membuka usahanya, dimana kedai tersebut mudah dijangkau, dan memilikitarget konsumen mahasiswa, dan karyawan UKP. Metode yang digunakan dalam penelitian ini adalah metode Critical Incident Technique (CIT) yang merupakan prosedur sistematis pada penelitian kualitatif untuk memperoleh informasi yang signifikan terkait dengan suatu insiden, peristiwa, atau proses non rutin berdasarkan pengalaman narasumber, dan pengamatam terhadap perilaku spesifik secara langsung (Flanagan, 1954). Pengumpulan data dengan metode CIT dapat dilakukan dengan wawancara pribadi, focus group interview, observasi secara langsung, atau secara partisipatif (Edvardsson, 1992). Dalam penelitian ini, pengumpulan data dilakukan melalui wawancara secara langsung dengan pemilik usaha kedai makanan di sekitar UKP yang masih membuka usahanya hingga saat ini. Instrumen wawancara menggunakan panduan pertanyaan deskriptif yang telah disiapkan, kemudian pertanyaan tersebut diberikan kepada responden secara terbuka, dan mendorong responden untuk mengingat kejadian dan dapat dengan bebas menceritakannya. Responden diberikan waktu sebelum mendeskripsikannya, dengan harapan dapat menjelaskan dari situasi awal munculnya masalah tersebut hingga langkah - langkah yang diambil. Dalam hal ini, responden tidak terikat dan tidak dibatasi pada suatu pertanyaan tertentu dari peneliti. Selain itu, metode CIT tidak memerlukan adanya hipotesis, sehingga memungkinkan peneliti menghasilkan suatu konsep dan teori berdasarkan pola yang dibentuk saat responden memberikan informasi (Olsen, Morten J.S., \& Bertil Thomasson, 1992).

Langkah-langkah yang dilakukan dalam CIT adalah sebagai berikut :

1. Tujuan penelitian ini adalah melakukan proses pengelolaan risiko kedai makanan di sekitar UKP. Insiden kritis dalam penelitian ini adalah pandemi COVID-19 yang berdampak pada diberlakukannya kegiatan belajar mengajar secara online di UKP.

2. Mempersiapkan kuesioner berupa pertanyaan terbuka.

3. Identifikasi risiko dilakukan melalui wawancara secara langsung dengan pemilik kedai makanan KFB, DG, dan SC.

4. Analisa risiko dilakukan dengan mengukur tingkat kemungkinan, dan dampak risiko, dan dibentukmatriks risiko dari 2 kriteria tersebut.

5. Evaluasi risiko dilakukan dengan menggunakan kriteria respon risiko.

6. Untuk risiko yang memerlukan penanganan lebih lanjut, maka akan dilakukan opsi penanganan risiko seperti menghindari risiko, menerima risiko, membagi risiko, dan mengurangi risiko.

7. Pelaporan berisi risiko dan penanganannya untuk diberikan kepada pihak kedai makanan.

\section{HASIL PENELITIAN DAN PEMBAHASAN}

\section{Gambaran Umum}

Kedai makanan yang masih membuka usahanya hingga saat penelitian ini dilakukan, dan berada di sekitar UKP dengan mayoritas konsumennya mahasiswa, dan karyawan UKP sebanyak 8 kedai. Dari jumlah tersebut sebanyak 5 kedai tidak bersedia untuk diwawancarai, sehingga wawancara dilakukan terhadap 3 kedai makanan, yaitu kedai KFB, DG, dan SC.

Ketiga kedai makanan tersebut menghadapi insiden kritis COVID-19 sejak tahun 2020, dan masih bertahan membuka usahanya hingga saat penelitian ini dilakukan.

\section{Proses Manajemen Risiko}

Proses manajemen risiko yang dilakukan meliputi tahap identifikasi risiko, analisa risiko, evaluasi risiko, penanganan risiko, dan berakhir pada pelaporan.

Beberapa keterangan yang berlaku umum dalam tahap manajemen risiko pada ketiga kedai makanan tersebut.

1. Kode risiko bermakna untuk masing-masing perusahaan, dimana kode ini dilakukan berdasarkan banyaknya risiko pada proses bisnisnya, yaitu proses bisnis utama, proses bisnis pendukung, dan proses bisnis penunjang. Semakin kecil kode risiko, maka risiko tersebut berada pada proses bisnis utama.

2. TKR (Tingkat Kemungkinan Risiko) menurut BPKP (2011) sebagai berikut :

- Very Likely $(V L)=$ Sangat sering terjadi

- Likely $(L)=$ Sering terjadi

- Possible $(P)=$ Kadang-kadang terjadi

- Unlikely $(U)=$ Jarang terjadi

- Very Unlikely $(V U)=$ Sangat jarang terjadi

3. DR (Dampak Risiko) menurut BPKP (2011) sebagai berikut :

- Negligible $(N)=$ Dampaknya sangat kecil

- Minor $(M i)=$ Dampaknya kecil

- Moderate $(M o)=$ Dampaknya cukup besar

- Significant $(\mathrm{Si})=$ Dampaknya besar besar

- Severe $(\mathrm{Se})=$ Dampaknya sangat kecil 
4. MT (Matriks) menurut Boers (2017) adalah sebagai berikut :

- Low $(L)=$ Tingkatan risiko rendah

- Low Medium $(L M)=$ Tingkatan risiko rendah cenderung menengah

- Medium $(M)=$ Tingkatan risiko menengah

- Medium High $(M H)=$ Tingkatan risiko menengah cenderung tinggi

- High $(H)=$ Tingkatan risiko tinggi

5. Range risiko sebagai berikut :

- Range Risiko 1-3 = Area warna hijau tua (Dapat diterima)

- Range Risiko 4-6 = Area warna hijau muda (Dipantau)

- Range Risiko 7-9 = Area warna kuning (Pengendalian manajemen)

- Range Risiko 10-14 = Area warna oranye (Menjadi perhatian manajemen)

- Range Risiko 15-25 = Area warna merah (Tidak dapat diterima)

\section{Proses Manajemen Risiko KFB}

Tabel 1. Identifikasi dan Kategori Risiko KFB

\begin{tabular}{|c|c|c|}
\hline $\begin{array}{l}\text { Kode } \\
\text { Risiko } \\
\end{array}$ & Nama Risiko & $\begin{array}{c}\text { Kategori } \\
\text { Risiko } \\
\end{array}$ \\
\hline $\mathrm{R} 1$ & Risiko COVID-19. & Proses \\
\hline $\mathrm{R} 2$ & Risiko kebakaran. & Bisnis \\
\hline R3 & $\begin{array}{l}\text { Risiko munculnya } \\
\text { kompetitor lain. }\end{array}$ & $\begin{array}{l}\text { Utama } \\
\text { (Core) }\end{array}$ \\
\hline $\mathrm{R} 4$ & $\begin{array}{l}\text { Risiko pergeseran } \\
\text { perilaku konsumen. }\end{array}$ & \\
\hline $\mathrm{R} 5$ & $\begin{array}{l}\text { Risiko harga sewa } \\
\text { tempat yang tinggi. }\end{array}$ & $\begin{array}{l}\text { Proses } \\
\text { Bisnis }\end{array}$ \\
\hline R6 & $\begin{array}{l}\text { Risiko pencurian oleh } \\
\text { pembeli. }\end{array}$ & $\begin{array}{l}\text { Pendukung } \\
\quad \text { (CSU) }\end{array}$ \\
\hline $\mathrm{R} 7$ & $\begin{array}{l}\text { Risiko keluhan dari } \\
\text { pelanggan. }\end{array}$ & \\
\hline R8 & $\begin{array}{l}\text { Risiko penipuan oleh } \\
\text { pembeli. }\end{array}$ & \\
\hline R9 & $\begin{array}{lr}\text { Risiko } & \text { kesalahan } \\
\text { dalam } & \text { mencatat } \\
\text { transaksi } & \text { sehingga } \\
\text { pembukuan } & \text { tidak } \\
\text { balance } & \\
\end{array}$ & \\
\hline R10 & $\begin{array}{l}\text { Risiko bahan baku } \\
\text { kadaluarsa. }\end{array}$ & \\
\hline $\mathrm{R} 11$ & $\begin{array}{l}\text { Risiko peningkatan } \\
\text { harga bahan baku. }\end{array}$ & \\
\hline $\mathrm{R} 12$ & $\begin{array}{l}\text { Risiko } \\
\text { kesalahpahaman } \\
\text { dengan supplier. }\end{array}$ & \\
\hline R13 & $\begin{array}{l}\text { Risiko makanan tidak } \\
\text { habis terjual. }\end{array}$ & \\
\hline R14 & $\begin{array}{l}\text { Risiko salah membuat } \\
\text { pesanan, jumlah }\end{array}$ & \\
\hline
\end{tabular}

pesanan tidak sesuai, dan kesalahpahaman dengan pihak ojek online.

\begin{tabular}{|c|c|c|}
\hline R15 & $\begin{array}{l}\text { Risiko pegawai tidak } \\
\text { jujur dalam bekerja. }\end{array}$ & $\begin{array}{l}\text { Proses } \\
\text { Bisnis }\end{array}$ \\
\hline R16 & $\begin{array}{l}\text { Risiko keselamatan } \\
\text { kerja. }\end{array}$ & $\begin{array}{l}\text { Penunjang } \\
\text { (Periphery) }\end{array}$ \\
\hline R17 & $\begin{array}{l}\text { Risiko akibat } \\
\text { pengurangan pegawai. }\end{array}$ & \\
\hline R18 & $\begin{array}{l}\text { Risiko } \\
\text { ketidakmampuan } \\
\text { pemilik membayar } \\
\text { pegawai dengan harga } \\
\text { yang tinggi. }\end{array}$ & \\
\hline R19 & $\begin{array}{l}\text { Risiko tidak dapat } \\
\text { menyaring pegawai } \\
\text { dengan kualitas yang } \\
\text { tinggi. }\end{array}$ & \\
\hline R20 & $\begin{array}{ll}\text { Risiko sampah } & \text { sisa } \\
\text { masakkan, } & \text { dan } \\
\text { sampah lainnya. } & \\
\end{array}$ & \\
\hline
\end{tabular}

Tabel 2. Analisa dan Evaluasi Risiko KFB

\begin{tabular}{|c|c|c|c|c|c|}
\hline \multirow{2}{*}{$\begin{array}{l}\text { Kode } \\
\text { Risiko }\end{array}$} & \multicolumn{3}{|c|}{$\begin{array}{l}\text { Analisa } \\
\text { Risiko }\end{array}$} & \multirow{2}{*}{$\begin{array}{l}\text { Range } \\
\text { Risiko }\end{array}$} & \multirow{2}{*}{$\begin{array}{c}\text { Kriteria } \\
\text { Risiko }\end{array}$} \\
\hline & TKR & DR & MT & & \\
\hline $\mathrm{R} 1$ & VU & $\mathrm{Se}$ & M & $7-9$ & $\begin{array}{l}\text { Pengendalian } \\
\text { manajemen }\end{array}$ \\
\hline $\mathrm{R} 2$ & VU & $\mathrm{Se}$ & M & $7-9$ & $\begin{array}{l}\text { Pengendalian } \\
\text { manajemen }\end{array}$ \\
\hline $\mathrm{R} 3$ & VU & $\mathrm{Si}$ & M & $7-9$ & $\begin{array}{l}\text { Pengendalian } \\
\text { manajemen }\end{array}$ \\
\hline $\mathrm{R} 4$ & VU & $\mathrm{Si}$ & M & $7-9$ & $\begin{array}{l}\text { Pengendalian } \\
\text { manajemen }\end{array}$ \\
\hline R5 & VU & $\mathrm{Si}$ & M & $7-9$ & $\begin{array}{c}\text { Pengendalian } \\
\text { manajemen }\end{array}$ \\
\hline R6 & $\mathrm{P}$ & $\mathrm{Mi}$ & LM & $4-6$ & Dipantau \\
\hline R7 & $\mathrm{U}$ & $\mathrm{Mi}$ & $\mathrm{LM}$ & $4-6$ & Dipantau \\
\hline R8 & $\mathrm{U}$ & $\mathrm{Mi}$ & LM & $4-6$ & Dipantau \\
\hline R9 & $\mathrm{P}$ & Mo & M & $7-9$ & $\begin{array}{c}\text { Pengendalian } \\
\text { manajemen }\end{array}$ \\
\hline R10 & $\mathrm{P}$ & $\mathrm{Mi}$ & LM & $4-6$ & Dipantau \\
\hline R11 & $\mathrm{U}$ & $\mathrm{Mi}$ & $\mathrm{LM}$ & $4-6$ & Dipantau \\
\hline R12 & $\mathrm{U}$ & $\mathrm{Mi}$ & $\mathrm{LM}$ & $4-6$ & Dipantau \\
\hline R13 & $\mathrm{VL}$ & $\mathrm{N}$ & LM & $4-6$ & Dipantau \\
\hline R14 & $\mathrm{P}$ & $\mathrm{Mi}$ & LM & $4-6$ & Dipantau \\
\hline $\mathrm{R} 15$ & $\mathrm{~L}$ & Mo & M & $7-9$ & $\begin{array}{l}\text { Pengendalian } \\
\text { manajemen }\end{array}$ \\
\hline R16 & $\mathrm{U}$ & $\mathrm{Mi}$ & LM & $4-6$ & Dipantau \\
\hline $\mathrm{R} 17$ & $\mathrm{VU}$ & $\mathrm{N}$ & $\mathrm{L}$ & $1-3$ & Dapat diterima \\
\hline R18 & VU & $\mathrm{Mi}$ & $\mathrm{L}$ & $1-3$ & Dapat diterima \\
\hline R19 & $\mathrm{U}$ & Mo & LM & $4-6$ & Dipantau \\
\hline R20 & $\mathrm{VL}$ & $\mathrm{N}$ & $\mathrm{LM}$ & $4-6$ & Dipantau \\
\hline
\end{tabular}

Page $\mid 10$ 
Tabel 3. Penanganan Risiko KFB

\begin{tabular}{|c|c|}
\hline $\begin{array}{l}\text { Kode } \\
\text { Risiko }\end{array}$ & Penanganan Risiko \\
\hline R1 & $\begin{array}{l}\text { Menjalankan operasional } \\
\text { dengan protokol kesehatan, dan keadaan } \\
\text { pasar, dan tingkat daya beli serta } \\
\text { permintaan konsumen. }\end{array}$ \\
\hline $\mathrm{R} 2$ & $\begin{array}{l}\text { Mengatur penempatan bahan yang } \\
\text { mudahterbakar, memperhatikan aturan, } \\
\text { dan prosedur kerja, melakukan } \\
\text { pengecekkan terhadap kelayakkan alat } \\
\text { masak, dan lingkungan dapur yang } \\
\text { kondusif, memiliki akses yang mudah } \\
\text { untuk menyelamatkan diri. }\end{array}$ \\
\hline $\mathrm{R} 3$ & $\begin{array}{l}\text { Menjaga kualitas makanan, dan } \\
\text { mengembangkan varian menu makanan } \\
\text { yang dijual. }\end{array}$ \\
\hline $\mathrm{R} 4$ & $\begin{array}{l}\text { Menjaga kualitas, dan mutu } \\
\text { makanan, meningkatkan pelayanan, dan } \\
\text { kebersihan tempat makan, menerima } \\
\text { kritik dan masukkan. }\end{array}$ \\
\hline R5 & $\begin{array}{l}\text { Pemilik berencana untuk membuka } \\
\text { tempat pujasera dengan menyewakan } \\
\text { tempat kosong untuk diisi oleh tenant- } \\
\text { tenant usaha lain, mempertahankan } \\
\text { mutu, dan kualitas makanan, } \\
\text { menambah varian menu makanan, } \\
\text { memperhatikan sistem pengelolaan } \\
\text { keuangan, dan kebijakan. }\end{array}$ \\
\hline R6 & $\begin{array}{l}\text { Meningkatkan pengawasan terhadap } \\
\text { pembeli agar dapat meminimalisir } \\
\text { kemungkinan terjadinya tindak } \\
\text { pencurian }\end{array}$ \\
\hline R7 & $\begin{array}{l}\text { Menerima masukkan terkait rasa } \\
\text { masakkan, menjaga mutu dan kualias } \\
\text { untuk mempertahankan customer } \\
\text { loyalty. }\end{array}$ \\
\hline R8 & $\begin{array}{l}\text { Menunggu hingga muncul notifikasi } \\
\text { dana telah masuk, melakukan } \\
\text { pengecekkan kembali terhadap uang } \\
\text { kembalian, dan meningkatkan } \\
\text { pengawasan, }\end{array}$ \\
\hline R9 & $\begin{array}{l}\text { Mengecek kembali jumlah transaksi } \\
\text { yang terjadi, dan pembukuan. }\end{array}$ \\
\hline R10 & $\begin{array}{l}\text { Pembelian bahan baku disesuaikan } \\
\text { kebutuhan, apabila terdapat bahan baku } \\
\text { kadaluarsa maka dibuang. }\end{array}$ \\
\hline R11 & $\begin{array}{l}\text { Pembelian bahan baku disesuaikan } \\
\text { dengan kebutuhan, tidak melakukan } \\
\text { stok bahan baku dalam jumlah yang } \\
\text { terlalu banyak agar tidak terbuang. }\end{array}$ \\
\hline R12 & $\begin{array}{l}\text { Menukarkan pesanan yang keliru, dan } \\
\text { melakukan pengecakan bahan baku }\end{array}$ \\
\hline
\end{tabular}

yang datang.

R13 Menjual porsi makanan sesuai tingkat permintaan konsumen, menjual kembali makanan yang tidak habis terjual di depot kepada tetangga sekitar rumah pemilik.

R14 Mengirimkan kembali pesanan yang kurang, memastikan bahwa makanan yang dibuat telah sesuai pesanan, konfirmasi dengan pihak ojek online.

R15 Menegur pegawai yang melakukan tindak kecurangan, meningkatkan pengawasan dan evaluasi pegawai.

R16 Menjelaskan prosedur kerja, bekerja sesuai dengan jam kerja, membangun lingkungan kerja yang kondusif.

R17 Risiko dapat diterima dan tidak perlu melakukan penanganan risiko.

R18 Risiko dapat diterima dan tidak perlu melakukan penanganan risiko.

R19 Menjelaskan prosedur kerja, training pegawai, dan mengadakan evaluasi kinerja terhadap pegawai.

R20 Mengumpulkan sampah bekas masakkan menjadi satu, kemudian di dibuang ke tempat pembuangan sampah.

\section{Proses Manajemen Risiko pada DG}

Tabel 4. Identifikasi dan Kategori Risiko DG

\begin{tabular}{|c|c|c|}
\hline $\begin{array}{l}\text { Kode } \\
\text { Risiko }\end{array}$ & Nama Risiko & $\begin{array}{l}\text { Kategori } \\
\text { Risiko }\end{array}$ \\
\hline R1 & $\begin{array}{ll}\text { Risiko } & \text { terpapar } \\
\text { COVID-19. } & \end{array}$ & \multirow{4}{*}{$\begin{array}{l}\text { Proses } \\
\text { Bisnis } \\
\text { Utama } \\
\text { (Core) }\end{array}$} \\
\hline $\mathrm{R} 2$ & Risiko kebakaran. & \\
\hline R3 & $\begin{array}{l}\text { Risiko munculnya } \\
\text { kompetitor lain. }\end{array}$ & \\
\hline $\mathrm{R} 4$ & $\begin{array}{l}\text { Risiko pemadaman } \\
\text { listrik. }\end{array}$ & \\
\hline R5 & $\begin{array}{l}\text { Risiko kehabisan } \\
\text { bahan baku. }\end{array}$ & \multirow{6}{*}{$\begin{array}{c}\text { Proses } \\
\text { Bisnis } \\
\text { Pendukung } \\
\text { (CSU) }\end{array}$} \\
\hline R6 & $\begin{array}{l}\text { Risiko bahan baku } \\
\text { kadaluarsa. }\end{array}$ & \\
\hline R7 & $\begin{array}{l}\text { Risiko peningkatan } \\
\text { harga bahan baku. }\end{array}$ & \\
\hline R8 & $\begin{array}{l}\text { Risiko keterlambatan } \\
\text { pengiriman } \\
\text { supplier. }\end{array}$ & \\
\hline R9 & $\begin{array}{lr}\text { Risiko salah } \\
\text { pengiriman, dan } \\
\text { pesanan tertukar oleh } \\
\text { supplier. }\end{array}$ & \\
\hline R10 & $\begin{array}{l}\text { Risiko keluhan dari } \\
\text { pembeli, dan ojek }\end{array}$ & \\
\hline
\end{tabular}




\begin{tabular}{ll}
\hline \hline \multicolumn{3}{l}{ online. } \\
\hline R11 & $\begin{array}{l}\text { Risiko pembeli tidak } \\
\text { mau bayar, dan } \\
\text { pembeli lupa bayar. }\end{array}$ \\
\hline R12 & $\begin{array}{l}\text { Risiko kesalahan } \\
\text { memberikan } \\
\text { kembalian kepada } \\
\text { pembeli. }\end{array}$ \\
\hline R13 & $\begin{array}{l}\text { Risiko salah membuat } \\
\text { pesanan, jumlah } \\
\text { pesanan yang diantar } \\
\text { tidak sesuai, dan } \\
\text { kesalahpahaman } \\
\text { dengan pihak ojek } \\
\text { online. }\end{array}$ \\
\hline R14 & $\begin{array}{l}\text { Risiko kesalahan } \\
\text { menginput pesanan, } \\
\text { pencatatan transaksi, } \\
\text { dan pembukuan tidak } \\
\text { balance. }\end{array}$ \\
\hline Risiko pencurian oleh \\
pegawai.
\end{tabular}

\begin{tabular}{cccccc}
\hline R6 & U & Mi & LM & $4-6$ & Dipantau \\
\hline R7 & L & Mo & M & $7-9$ & $\begin{array}{c}\text { Pengendalian } \\
\text { manajemen }\end{array}$ \\
\hline R8 & U & Mi & LM & $4-6$ & Dipantau \\
\hline R9 & U & Mi & LM & $4-6$ & Dipantau \\
\hline R10 & L & Mi & LM & $4-6$ & Dipantau \\
\hline R11 & U & Mi & LM & $4-6$ & Dipantau \\
\hline R12 & U & Mi & LM & $4-6$ & Dipantau \\
\hline R13 & P & Mi & LM & $4-6$ & Dipantau \\
\hline R14 & U & Mo & LM & $4-6$ & Dipantau \\
\hline R15 & U & Mi & LM & $4-6$ & Dipantau \\
\hline R16 & U & Mi & LM & $4-6$ & Dipantau \\
\hline R17 & L & Mo & M & $7-9$ & $\begin{array}{c}\text { Pengendalian } \\
\text { manajemen }\end{array}$ \\
\hline R18 & U & Mi & LM & $4-6$ & Dipantau \\
\hline R19 & VL & N & LM & $4-6$ & Dipantau \\
\hline R20 & P & Mi & LM & $4-6$ & Dipantau \\
\hline & & & & &
\end{tabular}

Tabel 6. Penanganan Risiko DG

\begin{tabular}{|c|c|}
\hline $\begin{array}{l}\text { Kode } \\
\text { Risiko }\end{array}$ & Penanganan Risiko \\
\hline R1 & $\begin{array}{l}\text { Menjalankan operasional sesuai } \\
\text { dengan protokol kesehatan, dan keadaan } \\
\text { pasar, dan tingkat daya beli serta } \\
\text { permintaan konsumen. }\end{array}$ \\
\hline $\mathrm{R} 2$ & $\begin{array}{l}\text { Mengatur penempatan bahan yang } \\
\text { mudahterbakar, memperhatikan aturan, } \\
\text { dan prosedur kerja, melakukan } \\
\text { pengecekkan terhadap kelayakkan alat } \\
\text { masak, dan lingkungan dapur yang } \\
\text { kondusif, memiliki akses yang mudah } \\
\text { untuk menyelamatkan diri. }\end{array}$ \\
\hline R3 & $\begin{array}{l}\text { Menjaga kualitas makanan, } \\
\text { meningkatkan mutu, menjual menu } \\
\text { yang belum banyak dijual, dan } \\
\text { mengembangkan varian menu makanan } \\
\text { yang dijual. }\end{array}$ \\
\hline $\mathrm{R} 4$ & $\begin{array}{l}\text { Freezer untuk menyimpan bahan baku } \\
\text { tidak } \\
\text { dibuka selama listrik mati. }\end{array}$ \\
\hline $\mathrm{R} 5$ & $\begin{array}{l}\text { Mengecek stok barang baku yang } \\
\text { masih ada, memesan bahan baku } \\
\text { kepada supplier ketika bahan basku } \\
\text { hampir habis, dan tidak menunggu } \\
\text { sampai bahan baku habis. }\end{array}$ \\
\hline R6 & $\begin{array}{l}\text { Bahan baku seperti daging ayam dibeli } \\
\text { setiap 3-4 hari sekali, langsung diolah, } \\
\text { dan } \\
\text { dimasukkan ke dalam freezer. } \\
\text { Sedangkan untuk bahan baku sayur } \\
\text { dibeli setiap hari, dan disimpan di } \\
\text { kulkas. Apabila terdapat bahan baku } \\
\text { yang kadaluarsa maka dibuang. }\end{array}$ \\
\hline R7 & $\begin{array}{l}\text { Menyajikan menu yang laku terjual, } \\
\text { dan menaikkan harga makanan sesuai }\end{array}$ \\
\hline
\end{tabular}

\begin{tabular}{cccccc}
\hline $\begin{array}{c}\text { Kode } \\
\text { Risiko }\end{array}$ & \multicolumn{2}{c}{$\begin{array}{c}\text { Analisa } \\
\text { Risiko }\end{array}$} & $\begin{array}{c}\text { Range } \\
\text { Risiko }\end{array}$ & $\begin{array}{c}\text { Kriteria } \\
\text { Risiko }\end{array}$ \\
\cline { 2 - 5 } R1 & VU & Se & M & $7-9$ & $\begin{array}{c}\text { Pengendalian } \\
\text { manajemen }\end{array}$ \\
\hline R2 & VU & Se & M & $7-9$ & $\begin{array}{c}\text { Pengendalian } \\
\text { manajemen }\end{array}$ \\
\hline R3 & VU & Si & M & $7-9$ & $\begin{array}{c}\text { Pengendalian } \\
\text { manajemen }\end{array}$ \\
\hline R4 & VU & Si & M & $7-9$ & $\begin{array}{c}\text { Pengendalian } \\
\text { manajemen }\end{array}$ \\
\hline R5 & VU & Mo & LM & $4-6$ & Dipantau \\
\hline
\end{tabular}




\begin{tabular}{|c|c|}
\hline & kenaikan harga bahan baku. \\
\hline R8 & $\begin{array}{l}\text { Memberikan masukkan kepada } \\
\text { supplier agar memperbaiki jam } \\
\text { pengantaran, dan mengingatkan } \\
\text { supplier untuk mengirimkan pesanan. }\end{array}$ \\
\hline R9 & $\begin{array}{l}\text { Pesanan yang salah ditukar kembali, } \\
\text { dan melakukan pengecekan bahan baku } \\
\text { yang diterima. }\end{array}$ \\
\hline $\mathrm{R} 10$ & $\begin{array}{l}\text { Mencari tahu penyebab keluhan, } \\
\text { memberikan ganti rugi, dan digunakan } \\
\text { sebagai kritik dan masukkan untuk } \\
\text { kedepannya }\end{array}$ \\
\hline R11 & $\begin{array}{l}\text { Menegur pembeli yang tidak mau } \\
\text { bayar, mengingatkan pembeli yang } \\
\text { lupa bayar, dan meningkatkan } \\
\text { pengawasan terhadap pembeli. }\end{array}$ \\
\hline R12 & $\begin{array}{l}\text { Pembayaran } \\
\text { menggunakan e-payment, mengecek } \\
\text { kembali kembalian yang diberikan } \\
\text { kepada pembeli. }\end{array}$ \\
\hline R13 & $\begin{array}{l}\text { Untuk jenis makanan yang masih bisa } \\
\text { disimpan maka disimpan dalam kulkas } \\
\text { dan dipanaskan. Untuk makanan yang } \\
\text { tidak bisa disimpan lama maka } \\
\text { diberikan untuk pegawai atau ojek } \\
\text { online. }\end{array}$ \\
\hline $\mathrm{R} 14$ & Menggunakan Microsoft Excel. \\
\hline R15 & $\begin{array}{l}\text { Memberi teguran kepada pegawai, } \\
\text { apabila } \\
\text { sudah sampai } 3 \text { kali maka pegawai } \\
\text { tersebut dipecat. Pemilik menyimpan } \\
\text { stok bahan baku, dan meningkatkan } \\
\text { pengawasan kinerja pegawai. }\end{array}$ \\
\hline R16 & $\begin{array}{l}\text { Menyediakan kotak P3K, membeli obat } \\
\text { ke } \\
\text { apotek, mengecek alat masak, dan } \\
\text { keadaan } \\
\text { dapur. }\end{array}$ \\
\hline $\mathrm{R} 17$ & $\begin{array}{l}\text { Melakukan weekly meeting untuk } \\
\text { mengevaluasi, menjelaskan prosedur } \\
\text { kerja, memberikan kritik, masukkan } \\
\text { dan meningkatkan pengawasan kinerja } \\
\text { pegawai. }\end{array}$ \\
\hline $\mathrm{R} 18$ & $\begin{array}{l}\text { Tugas dikerjakan oleh pegawai lain, } \\
\text { menegur pegawai yang tidak masuk } \\
\text { kerja, meningkatkan pengawasan } \\
\text { terhadap kinerja pegawai tersebut. }\end{array}$ \\
\hline R19 & $\begin{array}{l}\text { Sisa masakkan dikumpulkan menjadi } \\
\text { satu, dan ditaruh di tempat sampah } \\
\text { untuk diambil oleh tukang sampah. }\end{array}$ \\
\hline R20 & $\begin{array}{l}\text { Menyediakan penampungan sisa } \\
\text { makanan (grease strap), menyiramkan } \\
\text { air panas ke saluran pipa pembuangan. } \\
\text { Apabila terjadi penyumbatan di got, } \\
\text { maka dibersihkan. }\end{array}$ \\
\hline
\end{tabular}

\section{Proses Manajemen Risiko SC}

Tabel 7. Identifikasi dan Kategori Risiko SC

\begin{tabular}{|c|c|c|}
\hline $\begin{array}{l}\text { Kode } \\
\text { Risiko }\end{array}$ & Nama Risiko & $\begin{array}{c}\text { Kategori } \\
\text { Risiko }\end{array}$ \\
\hline R1 & $\begin{array}{ll}\text { Risiko } & \text { terpapar } \\
\text { COVID-19. } & \\
\end{array}$ & \multirow{3}{*}{$\begin{array}{l}\text { Proses Bisnis } \\
\text { Utama } \\
\text { (Core) }\end{array}$} \\
\hline $\mathrm{R} 2$ & Risiko kebakaran. & \\
\hline R3 & $\begin{array}{l}\text { Risiko adanya } \\
\text { kompetitor lain. }\end{array}$ & \\
\hline $\mathrm{R} 4$ & $\begin{array}{l}\text { Risiko keluhan dari } \\
\text { pembeli. }\end{array}$ & \multirow{10}{*}{$\begin{array}{l}\text { Proses Bisnis } \\
\text { Pendukung } \\
\text { (CSU) }\end{array}$} \\
\hline R5 & $\begin{array}{l}\text { Risiko kecurangan } \\
\text { yang dilakukan oleh } \\
\text { pembeli. }\end{array}$ & \\
\hline R6 & $\begin{array}{l}\text { Risiko pembeli lupa } \\
\text { bayar, } \\
\text { pembayaran dengan } \\
\text { uang palsu }\end{array}$ & \\
\hline R7 & $\begin{array}{lr}\text { Risiko kesalahan } \\
\text { dalam membuat } \\
\text { pesanan, dan pesanan } \\
\text { tertukar. }\end{array}$ & \\
\hline $\mathrm{R} 8$ & $\begin{array}{l}\text { Risiko kesalahan } \\
\text { memberikan } \\
\text { kembalian kepada } \\
\text { pembeli. }\end{array}$ & \\
\hline R9 & $\begin{array}{l}\text { Risiko kualitas, dan } \\
\text { mutu makanan. }\end{array}$ & \\
\hline $\mathrm{R} 10$ & $\begin{array}{l}\text { Risiko bahan baku } \\
\text { kadaluarsa. }\end{array}$ & \\
\hline R11 & $\begin{array}{l}\text { Risiko bahan baku } \\
\text { mengalami } \\
\text { peningkatan. }\end{array}$ & \\
\hline $\mathrm{R} 12$ & $\begin{array}{l}\text { Risiko } \\
\text { kesalahpahaman } \\
\text { dengan supplier. }\end{array}$ & \\
\hline R13 & $\begin{array}{l}\text { Risiko kesalahan } \\
\text { menginput pesanan, } \\
\text { pencatatan transaksi, } \\
\text { dan pembukuan tidak } \\
\text { balance. }\end{array}$ & \\
\hline R14 & $\begin{array}{l}\text { Risiko penurunan } \\
\text { kinerja pegawai. }\end{array}$ & \multirow{4}{*}{$\begin{array}{l}\text { Proses Bisnis } \\
\text { Penunjang } \\
\text { (Periphery) }\end{array}$} \\
\hline $\mathrm{R} 15$ & $\begin{array}{l}\text { Risiko akibat } \\
\text { pengurangan } \\
\text { pegawai. }\end{array}$ & \\
\hline R16 & $\begin{array}{ll}\text { Risiko sampah } \\
\text { masakkan. }\end{array}$ & \\
\hline R17 & $\begin{array}{l}\text { Risiko saluran pipa } \\
\text { tersumbat. }\end{array}$ & \\
\hline
\end{tabular}

Tabel 8. Analisa dan Evaluasi Risiko SC 


\begin{tabular}{|c|c|c|c|c|c|}
\hline \multirow[t]{2}{*}{$\begin{array}{l}\text { Kode } \\
\text { Risiko }\end{array}$} & \multicolumn{3}{|c|}{$\begin{array}{c}\text { Analisa } \\
\text { Risiko }\end{array}$} & \multirow[t]{2}{*}{$\begin{array}{l}\text { Range } \\
\text { Risiko }\end{array}$} & \multirow[t]{2}{*}{$\begin{array}{c}\text { Kriteria } \\
\text { Risiko }\end{array}$} \\
\hline & TKR & DR & MT & & \\
\hline $\mathrm{R} 1$ & VU & $\mathrm{Se}$ & M & $7-9$ & $\begin{array}{c}\text { Pengendalian } \\
\text { manajemen }\end{array}$ \\
\hline $\mathrm{R} 2$ & VU & $\mathrm{Se}$ & M & $7-9$ & $\begin{array}{c}\text { Pengendalian } \\
\text { manajemen }\end{array}$ \\
\hline $\mathrm{R} 3$ & VU & $\mathrm{Si}$ & M & $7-9$ & $\begin{array}{c}\text { Pengendalian } \\
\text { manajemen }\end{array}$ \\
\hline $\mathrm{R} 4$ & $\mathrm{P}$ & $\mathrm{Mi}$ & LM & $4-6$ & $\begin{array}{c}\text { Pengendalian } \\
\text { manajemen }\end{array}$ \\
\hline R5 & $\mathrm{U}$ & $\mathrm{Mi}$ & LM & $4-6$ & Dipantau \\
\hline R6 & $\mathrm{U}$ & $\mathrm{Mi}$ & LM & $4-6$ & Dipantau \\
\hline R7 & $\mathrm{L}$ & $\mathrm{Mi}$ & LM & $4-6$ & $\begin{array}{c}\text { Pengendalian } \\
\text { manajemen }\end{array}$ \\
\hline R8 & $\mathrm{U}$ & $\mathrm{Mi}$ & LM & $4-6$ & Dipantau \\
\hline R9 & $\mathrm{U}$ & $\mathrm{Mi}$ & LM & $4-6$ & Dipantau \\
\hline $\mathrm{R} 10$ & VU & Mo & LM & $4-6$ & Dipantau \\
\hline R11 & $\mathrm{U}$ & $\mathrm{Mi}$ & LM & $4-6$ & Dipantau \\
\hline R12 & $\mathrm{U}$ & $\mathrm{Mi}$ & LM & $4-6$ & Dipantau \\
\hline $\mathrm{R} 13$ & $\mathrm{U}$ & Mo & LM & $4-6$ & Dipantau \\
\hline $\mathrm{R} 14$ & $\mathrm{U}$ & $\mathrm{Mi}$ & LM & $4-6$ & Dipantau \\
\hline $\mathrm{R} 15$ & VU & $\mathrm{N}$ & $\mathrm{L}$ & $1-3$ & Dipantau \\
\hline $\mathrm{R} 16$ & VL & $\mathrm{N}$ & LM & $4-6$ & Dipantau \\
\hline $\mathrm{R} 17$ & $\mathrm{U}$ & $\mathrm{Mi}$ & LM & $4-6$ & $\begin{array}{c}\text { Pengendalian } \\
\text { manajemen }\end{array}$ \\
\hline $\mathrm{R} 18$ & $\mathrm{U}$ & $\mathrm{Mi}$ & LM & $4-6$ & Dipantau \\
\hline R19 & $\mathrm{P}$ & $\mathrm{Mi}$ & LM & $4-6$ & Dipantau \\
\hline $\mathrm{R} 20$ & $\mathrm{U}$ & $\mathrm{Mi}$ & LM & $4-6$ & Dipantau \\
\hline
\end{tabular}

\begin{tabular}{|c|c|}
\hline R5 & $\begin{array}{l}\text { Mengadakan training untuk } \\
\text { membedakan uang asli dengan uang } \\
\text { palsu dengan menggunakan sinar UV, } \\
\text { dan memastikan kembali bahwa } \\
\text { pembeli membayar sesuai nominal. }\end{array}$ \\
\hline R6 & $\begin{array}{l}\text { Mengingatkan pembeli untuk } \\
\text { membayar, } \\
\text { adanya perubahan kebijakan untuk } \\
\text { pemesanan makanan dalam jumlah } \\
\text { banya dimana pembayaran harus lunas } \\
\text { H-1. }\end{array}$ \\
\hline R7 & $\begin{array}{l}\text { Meminta maaf kepada pembeli atas } \\
\text { kesalahan yang terjadi, dan mengganti } \\
\text { pesanan yang tertukar dengan pesanan } \\
\text { yang benar. }\end{array}$ \\
\hline R8 & $\begin{array}{l}\text { Mengadakan training kepada pegawai } \\
\text { terkait prosedur dalam melakukan } \\
\text { transaksi, dan melakukan pengecekkan } \\
\text { kembali. }\end{array}$ \\
\hline R9 & $\begin{array}{l}\text { Meminta maaf kepada pembeli, dam } \\
\text { mengganti secara penuh makanan yang } \\
\text { gosong dengan makanan baru. }\end{array}$ \\
\hline R10 & $\begin{array}{l}\text { Menjual menu yang paling laku terjual, } \\
\text { tidak melakukan stok bahan baku } \\
\text { dalam jumlah yang banyak, dan } \\
\text { membeli bahan baku setiap hari untuk } \\
\text { menjaga kualitas. }\end{array}$ \\
\hline R11 & $\begin{array}{l}\text { Apabila kenaikan harga bahan baku } \\
\text { masih bisa diterima, dan ditoleransi } \\
\text { maka harga makanan tidak akan naik, } \\
\text { namun apabila harga bahan baku sudah } \\
\text { tidak dapat diterima, dan ditoleransi, } \\
\text { maka harga makanan dinaikkan. }\end{array}$ \\
\hline $\mathrm{R} 12$ & $\begin{array}{l}\text { Mengajukan keluhan kepada supplier, } \\
\text { dan } \\
\text { melakukan penjadwalan ulang terhadap } \\
\text { pengiriman bahan baku. }\end{array}$ \\
\hline $\mathrm{R} 13$ & $\begin{array}{l}\text { Apabila kesalahan membuat pesanan } \\
\text { berasal dari pihak pegawai, maka } \\
\text { pegawai harus bertanggung jawab } \\
\text { untuk mengganti, namun apabila } \\
\text { kesalahan bukan dari pihak pegawai } \\
\text { melainkan dari sistem, maka pemilik } \\
\text { SC yang menanggung. Selain itu, } \\
\text { melakukan audit harian, mingguan, dan } \\
\text { bulanan, menggunakan software } \\
\text { counting dan software point of sales } \\
\text { untuk pembukuan secara otomatis. }\end{array}$ \\
\hline R14 & $\begin{array}{l}\text { Mengadakan evaluasi rutin terhadap } \\
\text { kinerja pegawai, mengadakan training } \\
\text { pegawai terkait dengan customer } \\
\text { service, pelatihan sistem keuangan, dan } \\
\text { workflow. }\end{array}$ \\
\hline R15 & $\begin{array}{l}\text { Risiko masih dapat diterima, dan tidak } \\
\text { memerlukan penanganan risiko lebih } \\
\text { lanjut. }\end{array}$ \\
\hline R16 & Menggunakan perangkat khusus untuk \\
\hline
\end{tabular}

\begin{tabular}{|c|c|}
\hline $\begin{array}{l}\text { Kode } \\
\text { Risiko }\end{array}$ & Penanganan Risiko \\
\hline $\mathrm{R} 1$ & $\begin{array}{l}\text { Menjalankan operasional sesuai } \\
\text { dengan protokol kesehatan, dan keadaan } \\
\text { pasar, dan tingkat daya beli serta } \\
\text { permintaan konsumen. }\end{array}$ \\
\hline $\mathrm{R} 2$ & $\begin{array}{l}\text { Mengatur penempatan bahan yang } \\
\text { mudahterbakar, memperhatikan aturan, } \\
\text { dan prosedur kerja, melakukan } \\
\text { pengecekkan terhadap kelayakkan alat } \\
\text { masak, dan lingkungan dapur yang } \\
\text { kondusif, memiliki akses yang mudah } \\
\text { untuk menyelamatkan diri. }\end{array}$ \\
\hline R3 & $\begin{array}{l}\text { Menjaga kualitas makanan, menerima } \\
\text { kritik masukkan, mencari tahu tingkat } \\
\text { permintaan konsumen, menyesuaikan } \\
\text { harga, dan mengembangkan varian } \\
\text { menu makanan yang dijual. }\end{array}$ \\
\hline $\mathrm{R} 4$ & $\begin{array}{l}\text { Mencari tahu penyebab keluhan, } \\
\text { meminta maaf, mengganti rugi, dan } \\
\text { menjadikannya masukkan untuk } \\
\text { kedepannya. }\end{array}$ \\
\hline
\end{tabular}




\begin{tabular}{ll}
\hline \hline & limbah tempat makan, yaitu grease \\
& trap, untuk dikumpulkan jadi satu, dan \\
& diambil oleh tukang sampah. \\
\hline R17 & Memanggil tukang untuk \\
& membersihkan pipa yang tersumbat, \\
& mengadakan general cleaning setiap 1 \\
& bulan sekali untuk memastikan \\
& peralatan masak dalam keadaan yang \\
& layak. \\
\hline R18 & Memberikan prosedur terkait peraturan, \\
& dan pengaturan stok barang, serta \\
& training tools, dan waste. Apabila \\
& melakukan suatu kesalahan, maka \\
& pegawai tersebut bertanggung jawab \\
& untuk memperbaiki kesalahannya. \\
\hline R19 & Menaikkan tempat SC menjadi lebih \\
& tinggi, sehingga apabila terjadi hujan \\
& deras, air banjir tidak masuk ke dalam \\
kedai. & Menyediakan kotak P3K, memberikan \\
training kepada pegawai terkait \\
prosedur dalam bekerja.
\end{tabular}

\section{PENUTUP}

\section{Kesimpulan}

Terdapat 60 risiko operasional yang diidentifikasi dari ketiga kedai makanan, dimana masing - masing kedai tersebut menghadapi 20 risiko operasional. Risiko-risiko tersebut tersebar pada 3 kategori bisnis yang berbeda, mayoritas risiko berada pada proses bisnis pendukung.

Risiko yang sama dapat tersebar pada kategori risiko yang berbeda pada masing - masing kedai makanan. Kategori risiko yang berbeda ini diakibatkan oleh adanya selera risiko yang berbeda dari masing - masing kedai makanan terhadap risiko usaha.

Saat ini, matriks risiko pada ketiga kedai makanan yang diteliti berada pada tingkatan rendah cenderung menengah, namun hal ini dapat berubah seiring dengan berjalannya waktu.

\section{Saran}

Mayoritas risiko berada pada proses bisnis pendukung yang memiliki dampak relatif ringan, namun demikian tidak berarti pemilik melalaikan risiko pada proses bisnis utama yang sama dihadapi oleh ketiga kedai makanan tersebut, seperti risiko COVID-19 dimana pemilik perlu melihat tingkat permintaan konsumen, menjual menu yang memiliki minat tinggi di masyarakat, memiliki kebijakkan dalam mengelola usaha, dan memperhatikan protokol kesehatan. Untuk risiko kebakaran diperlukan kondisi dapur, dan alat masak yang layak, memperhatikan penempatan bahan yang mudah terbakar, melakukan training untuk sigap kebakaran, serta memiliki akses yang mudah untuk menyelamatkan diri. Untuk menghadapi risiko adanya kompetitor lain pemilik perlu untuk melihat kondisi pasar, mempertahankan, dan meningkatkan kualitas, mutu, dan layanan.

Risiko pada proses bisnis penunjang yang dihadapi oleh ketiga kedai makanan berkaitan dengan kinerja pegawai, dimana dalam menyikapinya diperlukan adanya traning, dan evaluasi kinerja pada pegawai tersebut.

\section{DAFTAR PUSTAKA}

Alquier, A. B., \& Tignol, M. L. (2006). Risk management in small-and medium-sized enterprises. Production Planning and Control, 17(3), 273-282.

Basyaib, F. (2007). Manajemen Risiko. Jakarta: PT Grasindo.

Bitner, Mary Jo, Bernard H. Booms, \& Lois A. Mohr. (1994). Critical Service Encounters: The Employee's View. Journal of Markketing, 58 (October), 95-106.

Boers, D. (2017, September 13). ARMS Reliability. Retrieved from BEYOND THE RISK MATRIX:

https://www.thereliabilityblog.com/2017/09/1 3/beyond-the-risk-matrix/

BPKP. (2011, November 10). PERATURAN KEPALA BADAN PENGAWASAN KEUANGAN DAN PEMBANGUNAN. Retrieved from PEDOMAN PENYELENGGARAAN SISTEM PENGENDALIAN INTERN PEMERINTAH PADA SEKRETARIAT UTAMA BADAN PENGAWASAN KEUANGAN DAN PEMBANGUNAN: www.bpkp.go.id

Chitakornjisil. (2009). Risiko Operasional. Jakarta: Gramedia Pustaka Utama.

Djohanputro, B. (2006). Manajemen Risiko Korporat Terintegrasi. Jakarta: PPM.

Duckert, G. (2011). Practical enterprise risk management: a business process approach. Wiley: Hoboken.

Edvardsson, B. (1992). Service Breakdowns: A Study of Critical Incidents in an Airline. International Journal of Service Industri Management, 24 (February), 99-116.

Fahmi, I. (2010). Manajemen Risiko. Bandung: Alfabeta.

Fatoki, \& Olawale. (2014). The Financial Literacy of Micro Entrepreneurs in South Africa. J See Sel. Vol 40, 2.

Flanagan, J. (1954). The Critical Incident Technique. Psychological Bulletin, 51(4), 327-357.

Hanafi. (2006). Manajemen Risiko Operasional. Jakarta: Pendidikan dan Pembinaan Manajemen. 
Hendro. (2011). Dasar-Dasar Kewirausahaan Panduan bagi Mahasiswa untuk Mengenal, Memahami, dan Memasuki Dunia Bisnis. Jakarta: Erlangga.

Islam, M., J D, T., \& E, H. (2008). Managing operational risks in small-and medium-sized enterprises (SMEs) engaged inn manufacturing-an integrated approach. International Journal of Technology, Policy and Management, 8(4), 420-441.

ISO 31000, I.(2018).ISO 31000:2018 Risk Management - Guidelines.Switzerland: ISO Organization.

Kasidi. (2010). Manajemen Risiko. Bogor: Ghalia Indonesia.

Kasidi. (2014). Manajemen Risiko. Bogor: Ghalia Indonesia.

Kountur, R. (2016). Cara Mudah Asesmen Risiko Terintegrasi: Quantitative Approach. Jakarta: PT. Rap Indonesia.

Moeller, R. (2009). Brink's Modern Internal Auditing, a Common Body of Knowledge. Canada: Wiley.

Ntlhane, K. (1995). The application of risk management principles to smaller enterprises. research report submitted in partial fulfillment of the requirements for the degree of Masters of Business Administration in the Faculty of Management at the University of the Witwater.

Olsen, Morten J.S., \& Bertil Thomasson. (1992). "Studies in Service Quality with the Aid of Critical Incidents and Phenomenography," in QUIS 3: Quality in Services Conference, Eberhard E. Scheuing, Bo Edvardsson, David Lascelles, and Charles H. Little. eds. Jamaica: NY: International Service Quality Association.

Silvestri, A., Cagno, E., \& Trucco, P. (2009). On the Anatomy of Operational Risk. IEEE Journal, 978-1-4244-4870-8/09.

Stauss, B. (1993). "Using the Critical Incident Technique in Measur- ing and Managing Service Quality" in The Service Quality Handbook, Eberhard E. Scheuing and William F. Christopher. eds. New York: American Management Association.

Sugiyono. (2017). Metode Penelitian Kuantitatif Kualitatif dan $R \& D$. Bandung: Alfabeta.

The Portfolio Committee on Small and Medium Cooperative Development. (2010).

Umar, H. (1998). Riset Sumberdaya Manusia Dalam Organisasi. Jakarta: PT. Gramedia Pustaka Utama.

\section{Profil Penulis}

1. Graciella Valentina, Mahasiswa Program Finance and Investment, Universitas Kristen Petra, Jl. Siwalankerto 121-131, Surabaya.

Email: d11170440@john.petra.ac.id

2. Pwee Leng, S.E., S.H., M.Kom., Dipl.IFF, Program Finance and Investment, Universitas Kristen Petra Surabaya, J1. Siwalankerto 121-131, Surabaya.

Email:pweeleng@petra.ac.id 